ARTICLE

\title{
Mitigation potential of global ammonia emissions and related health impacts in the trade network
}

\author{
Rong Ma1,12, Ke Li (i) 2,3,12, Yixin Guo (1) 4,11, Bo Zhang ${ }^{5 凶}$, Xueli Zhao ${ }^{5}$, Soeren Linder ${ }^{6}$, ChengHe Guan7, \\ Guoqian Chen (1) ${ }^{8}$, Yujie Gan ${ }^{9}$ \& Jing Meng (1) ${ }^{10 凶}$
}

Ammonia $\left(\mathrm{NH}_{3}\right)$ emissions, mainly from agricultural sources, generate substantial health damage due to the adverse effects on air quality. $\mathrm{NH}_{3}$ emission reduction strategies are still far from being effective. In particular, a growing trade network in this era of globalization offers untapped emission mitigation potential that has been overlooked. Here we show that about one-fourth of global agricultural $\mathrm{NH}_{3}$ emissions in 2012 are trade-related. Globally they induce 61 thousand $\mathrm{PM}_{2.5}$-related premature mortalities, with 25 thousand deaths associated with crop cultivation and 36 thousand deaths with livestock production. The trade-related health damage network is regionally integrated and can be characterized by three trading communities. Thus, effective cooperation within trade-dependent communities will achieve considerable $\mathrm{NH}_{3}$ emission reductions allowed by technological advancements and trade structure adjustments. Identification of regional communities from network analysis offers a new perspective on addressing $\mathrm{NH}_{3}$ emissions and is also applicable to agricultural greenhouse gas emissions mitigation.

\footnotetext{
${ }^{1}$ School of Economics and Management, Beihang University, Beijing, China. ${ }^{2}$ Harvard-NUIST Joint Laboratory for Air Quality and Climate, Jiangsu Key Laboratory of Atmospheric Environment Monitoring and Pollution Control, Collaborative Innovation Center of Atmospheric Environment and Equipment Technology, School of Environmental Science and Engineering, Nanjing University of Information Science and Technology, Nanjing, China. ${ }^{3}$ John A. Paulson School of Engineering and Applied Sciences, Harvard University, Cambridge, MA, USA. ${ }^{4}$ Princeton School of Public and International Affairs, Princeton University, Princeton, NJ, USA. ${ }^{5}$ School of Management, China University of Mining and Technology (Beijing), Beijing, China. ${ }^{6}$ Joint Research Centre, Food Security Group, European Commissions, Ispra, Italy. ${ }^{7}$ Arts and Science, New York University Shanghai, Shanghai, China. ${ }^{8}$ Laboratory of Systems Ecology and Sustainability Science, College of Engineering, Peking University, Beijing, China. ${ }^{9}$ School of Government, The Leo KoGuan Building, Peking University, 100871 Beijing, China. ${ }^{10}$ The Bartlett School of Sustainable Construction, University of College London, London WC1E 7HB, UK. ${ }^{11}$ Present address: Laboratory for Climate and Ocean-Atmosphere Studies, Department of Atmospheric and Oceanic Sciences, School of Physics, Peking University, Beijing, China. ${ }^{12}$ These authors contributed equally: Rong Ma, Ke Li. ${ }_{\text {email: zhangbo@cumtb.edu.cn; jing.j.meng@ucl.ac.uk }}$
} 
W ith air pollution being reduced globally by controlling pollutants from industrial sectors, the far-lessregulated ammonia $\left(\mathrm{NH}_{3}\right)$ emissions consequently become an important driver for fine particulate matter $\left(\mathrm{PM}_{2.5}\right)$ pollution ${ }^{1-4}$. $\mathrm{NH}_{3}$ emissions contribute to $\mathrm{PM}_{2.5}$ pollution through the chemical formation of particulate ammonium sulfate and ammonium nitrate ${ }^{4,5}$ and lead to tens of thousands of deaths annually ${ }^{6}$. Nearly $90 \%$ of global $\mathrm{NH}_{3}$ emissions are emitted from agricultural sources ${ }^{1}$, including ammonia-based fertilizers and animal manure. Unfortunately, regulations for agricultural $\mathrm{NH}_{3}$ emissions are overall ineffective worldwide ${ }^{1}$. Outpacing many industrial sectors, agriculture is the leading sector in driving anthropogenic $\mathrm{PM}_{2.5}$ pollution in Europe and the eastern $\mathrm{USA}^{4,6,7} \cdot \mathrm{NH}_{3}$ emissions are currently not regulated over high $\mathrm{NH}_{3}$ emitting regions, e.g., China ${ }^{1}$, although recent research shows that improving agricultural nitrogen management can achieve $34 \%$ reductions and reduce $\mathrm{PM}_{2.5}$ by up to $8 \mu \mathrm{g} \mathrm{m}^{-3}$ (ref. ${ }^{8}$ ) More importantly, future increases in agricultural production to accommodate food demand of a growing population will increase the health risks from $\mathrm{NH}_{3}$-related environmental consequences ${ }^{9,10}$. As such, developing strategies to reduce $\mathrm{NH}_{3}$ emissions is urgent and would generate substantial environmental and health benefits $1,6,8,11$.

Substantial efforts have already been made to reduce pollutant emissions at local scales ${ }^{1,8}$. In a globalized world, however, localized agricultural production is increasingly connected to foreign consumption owing to the expanding agricultural trade in order to meet food and nutritional demands around the world ${ }^{12}$. The current trade volume of global agricultural commodities accounts for over $20 \%$ of global agricultural production ${ }^{13}$, mostly occurring between Organisation for Economic Cooperation and Development (OECD) and non-OECD countries (such as China, India, and other Asian countries). Substantial $\mathrm{NH}_{3}$ emissions are related to international exports of agricultural commodities by mostly developing countries to meet the growing food demand of the developed world ${ }^{14}$. Understanding $\mathrm{NH}_{3}$ emissions embodied in international trade offers considerable potential to abate $\mathrm{NH}_{3}$ emissions.

$\mathrm{NH}_{3}$ emission transfers through the global trade network can be quantified by global multiregional input-output (MRIO) models, which have been applied to measure trade-induced emissions of greenhouse gases ${ }^{15-18}$, primary $\mathrm{PM}_{2.5}$, and secondary $\mathrm{PM}_{2.5}$ precursors ${ }^{19-25}$. Oita et al. ${ }^{14}$ reported that about $26 \%$ of $\mathrm{NH}_{3}$ emissions in 2010 were embodied in the international trade of commodities. However, little attention was paid to the related public health burden, except for several recent analyses on the health impact of trade-related primary $\mathrm{PM}_{2.5}{ }^{23-25}$ and secondary $\mathrm{PM}_{2.5}$ precursors ${ }^{22}$. Although these studies shed light on the international dimension of consumption-driven environmental pollution and related health risks, their insights into each type of air pollutant have been counteracted because of the different sources and mitigation potential. Especially, previous studies focused mainly on pollutant emissions from industrial sectors, and agricultural $\mathrm{NH}_{3}$ emission transfers and their environmental and health outcomes are still not fully understood ${ }^{1}$.

Furthermore, transfers of the health burdens from traderelated $\mathrm{NH}_{3}$ emissions are determined by the structure of the international trade of agricultural commodities. Comparative advantages, such as availability of arable land, water resources, technologies, and geographical location, prompt various economies to participate in the production, processing, and trade of agricultural commodities. Those interregional activities transfer $\mathrm{NH}_{3}$ emissions and their health outcomes, together weaving a complex network ${ }^{26}$. Unveiling the network characteristics of health-effect transfers can target important regions, production sectors, consumption categories, and communities for reducing $\mathrm{NH}_{3}$ emissions and mitigating health damages.

In this work, we aim to explore the mitigation potential of global ammonia emissions by analyzing the role of the international trade network. We show the trade-induced global agricultural $\mathrm{NH}_{3}$ emissions, consequent $\mathrm{PM}_{2.5}$ formation and related health impacts of the year 2012 in 181 economies, demonstrating large $\mathrm{NH}_{3}$ mitigation potential in international trade and associated benefits. We identify the role of leading communities in transferring the health impacts through international trade. We further demonstrate the potential of technological advancements and trade structure adjustments within leading countries in reducing trade-related $\mathrm{NH}_{3}$ emissions. These findings point out the importance of international collaborative efforts for the formulation of comprehensive international environmental policies and actions for addressing $\mathrm{NH}_{3}$ that are overlooked.

\section{Results}

Health burdens of trade-related $\mathrm{NH}_{3}$ emissions. Global tradeinduced $\mathrm{NH}_{3}$ emissions of the year 2012 are assessed using the MRIO model with detailed $\mathrm{NH}_{3}$ emissions estimates from the Emissions Database for Global Atmospheric Research (EDGAR v4.3.2) inventory ${ }^{27}$ (see "Methods"). Since agricultural $\mathrm{NH}_{3}$ emissions $(52,325 \mathrm{Gg})$ account for $89 \%$ of the global $\mathrm{NH}_{3}$ emissions $(58,671 \mathrm{Gg})$ in 2012, we focus on $\mathrm{NH}_{3}$ emissions from the agricultural sector in this study. The embodied $\mathrm{NH}_{3}$ emissions in international trade balance (EEB) can be obtained as the difference of import-related emissions (EEI, total emissions in other regions related to domestic consumption) and export-related emissions (EEE, the total domestic emissions related to final consumption in other regions) (see Fig. 1 and "Methods"). An economy with a positive value of EEB is a net importer of embodied $\mathrm{NH}_{3}$ emissions, while that with a negative EEB is a net exporter. By linking the local emissions to global consumption, an estimated $23 \%(11,840 \mathrm{Gg})$ of global agricultural productionbased emissions (PBEs), namely emissions caused by domestic production, are associated with international exports (Fig. 1a and Supplementary Data 1). Our estimation is consistent with the previously reported $26 \%$ of $\mathrm{NH}_{3}$ emissions embodied in the international trade in $2010^{14}$. Owing to such substantial agricultural $\mathrm{NH}_{3}$ emissions embodied in international trade, the PBE of $\mathrm{NH}_{3}$ in most economies are remarkably different from their consumption-based emissions (CBEs), which allocate emissions occurring during food production and distribution to final consumers (Fig. 1b and Supplementary Data 2). It thus means that global transfers of agricultural $\mathrm{NH}_{3}$ emissions (Supplementary Data 3 and Supplementary Table 1) can reallocate $\mathrm{PM}_{2.5}$ and public health burdens across borders, i.e., improving (harming) air quality and health in importing (exporting) countries.

We quantify the contribution of trade-related $\mathrm{NH}_{3}$ emissions to $\mathrm{PM}_{2.5}$ exposure by utilizing a global chemical transport model (CTM) (GEOS-Chem) by perturbing $\mathrm{NH}_{3}$ emissions embodied in exported products (export-related emissions) for 181 countries (see "Methods"). Figure 2a shows that $\mathrm{NH}_{3}$ emissions resulting from producing final products that are ultimately consumed abroad occur in many developing countries, with adverse effects on local air quality. About 1-2 $\mu \mathrm{g} \mathrm{m}^{-3}$ of $\mathrm{PM}_{2.5}$ in eastern China is contributed by agricultural $\mathrm{NH}_{3}$ emitted during the production of food that is exported. We found a similar magnitude of contributions to local $\mathrm{PM}_{2.5}$ for export in other countries, i.e., $0.6-1.2 \mu \mathrm{g} \mathrm{m}^{-3}$ in northern India and Pakistan, $0.6-1.5 \mu \mathrm{g} \mathrm{m}^{-3}$ in northern Italy and eastern European countries (e.g., Poland, Belarus, Ukraine), and $0.3-0.9 \mu \mathrm{g} \mathrm{m}^{-3}$ in the eastern USA and central Canada. 

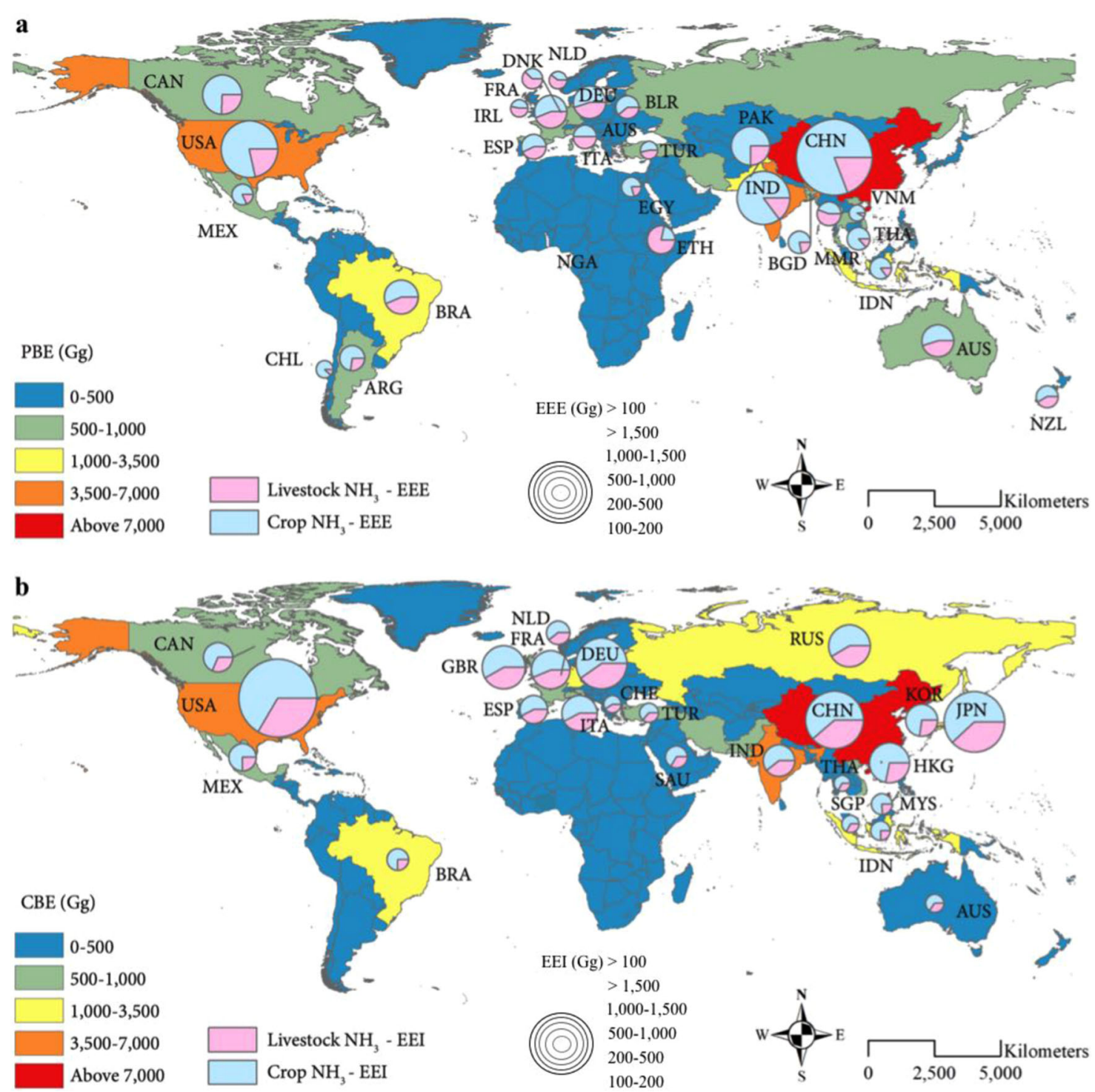

Fig. 1 Global agricultural $\mathrm{NH}_{3}$ emissions associated with production, consumption, and trade. a Production-based emissions (PBEs) of $\mathrm{NH}_{3}$ (shaded) and export-related emissions (EEEs) of $\mathrm{NH}_{3}$ (pie charts) (Gg) in 2012. Pie charts inserted in (a) are the countries (highlighted by country's abbreviation) with high EEE $\mathrm{NH}_{3}$ emissions from livestock and crop cultivation, respectively. b Consumption-based (CBE) and import-related emissions (EEls) of $\mathrm{NH}_{3}$ (Gg) in 2012. Detailed results for each country are provided in the Supplementary Data files. The three-letter country abbreviations inserted in the plot are detailed in Supplementary Data 6. Maps were created by using ArcGIS version 10.7.1 (ESRI https://www.esri.com/en-us/arcgis/about-arcgis/overview).

The associated public health burden is estimated using the integrated exposure-response (IER) functions following the method of the Global Burden of Disease (GBD) $\operatorname{study}^{28}$ (see "Methods"). The estimated premature deaths attributed to ambient $\mathrm{PM}_{2.5}$ exposure is a function of export-related $\mathrm{NH}_{3}$ emissions, local $\mathrm{PM}_{2.5}$ levels, population densities, and baseline mortality for different diseases. Here we consider the impacts from the four leading causes of death: ischemic heart disease, chronic obstructive pulmonary disease, cerebrovascular disease, and lung cancer. We estimated the mortality contribution from sectoral export-related agricultural $\mathrm{NH}_{3}$ emissions based on an assumption that the contribution of one sector to the disease burden of $\mathrm{PM}_{2.5}$ is directly proportional to its share of $\mathrm{PM}_{2.5}$ concentration.

For a given country, the premature deaths from its sectoral export-related $\mathrm{NH}_{3}$ emissions can be calculated by multiplying its fractional contribution of sectoral export-related $\mathrm{NH}_{3}$ emissions to $\mathrm{PM}_{2.5}$ concentration by the total $\mathrm{PM}_{2.5}$ concentration-related mortalities for each $0.1^{\circ} \times 0.1^{\circ}$ grid cell. The fractional contribution of sectoral export-related $\mathrm{NH}_{3}$ emissions to $\mathrm{PM}_{2.5}$ was estimated by the GEOS-Chem simulations (see "Methods"). The export-related $\mathrm{NH}_{3}$ emissions are related to 61 thousand premature deaths, especially in many developing countries (Supplementary Fig. 1 and Supplementary Table 2). High premature mortality is found in China (26.3 thousand deaths) and India (6.2 thousand deaths), due to their higher $\mathrm{PM}_{2.5}$ concentrations from export-related agricultural $\mathrm{NH}_{3}$ emissions and population densities. In Southeast Asia, premature mortality is estimated at about 2.0 thousand deaths, of which Bangladesh and Vietnam account for 45\% (0.9 thousand deaths) and 32\% (0.7 thousand deaths). In Pakistan, $37 \%$ of agricultural $\mathrm{NH}_{3}$ emissions and 0.9 thousand deaths are related to exports. $\mathrm{PM}_{2.5}$ pollution from export-related $\mathrm{NH}_{3}$ emissions is responsible for 2.1 thousand deaths in the USA. In Europe, the estimated premature mortality in Eastern European countries (9.7 thousand deaths) is much higher than those in Western Europe (3.9 thousand deaths).

Figure $2 b, c$ shows the health burdens estimated from sectoral export-related $\mathrm{NH}_{3}$ emissions. Premature mortality induced by 

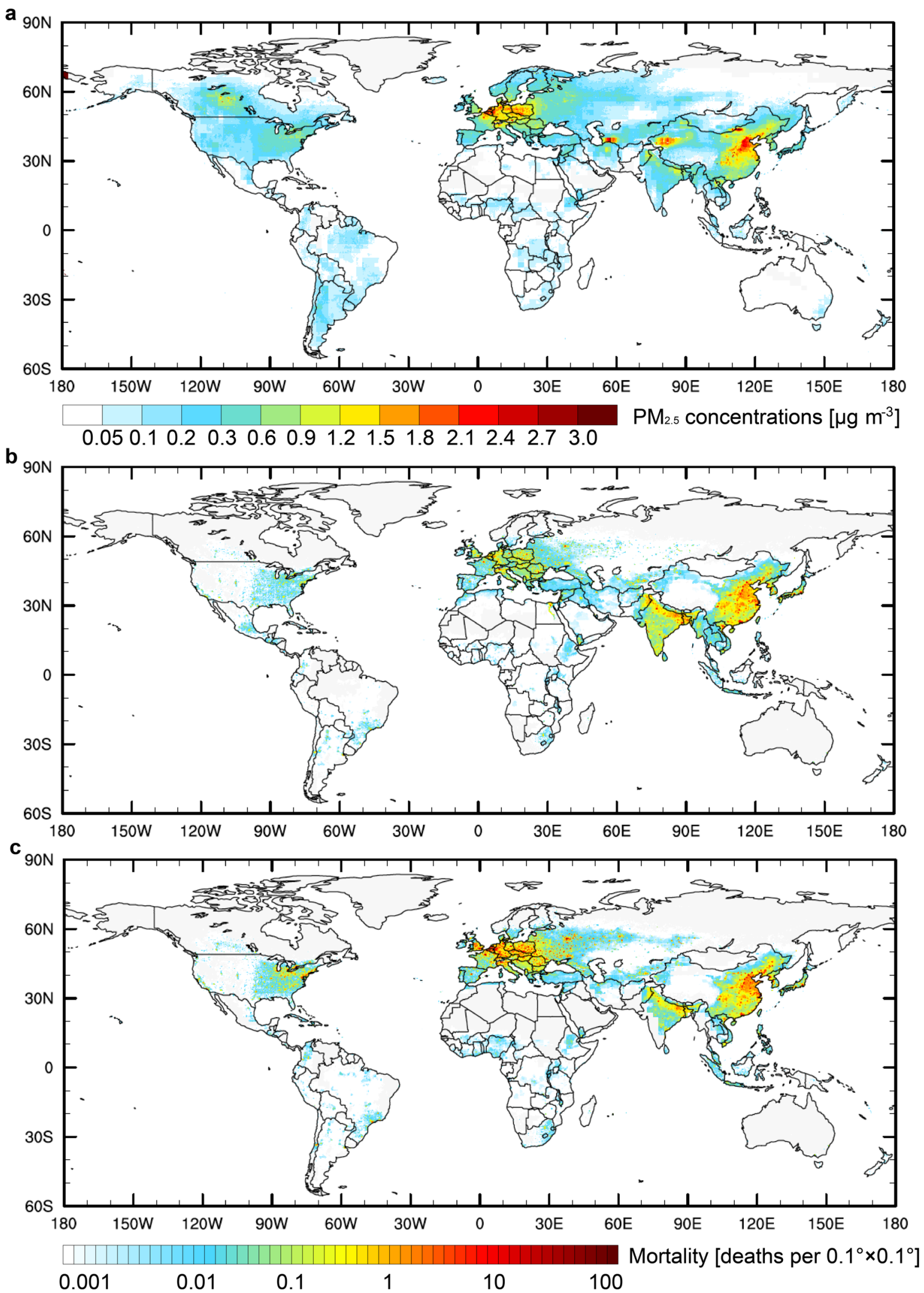

Fig. 2 Air quality and health impacts of export-related $\mathbf{N H}_{\mathbf{3}}$ emissions in $\mathbf{2 0 1 2}$. a $\mathrm{PM}_{2.5}$ concentrations ( $\mu$ g $\mathrm{m}^{-3}$ ) induced by export-related $\mathrm{NH}_{3}$ emissions in 2012 are calculated by GEOS-Chem simulations. Attributable premature mortality density (deaths per $0.1^{\circ} \times 0.1^{\circ} \mathrm{a}^{-1}$ ) due to export-related $\mathrm{NH}_{3}$ emissions from $\mathbf{b}$ crop production and $\mathbf{c}$ livestock production. The attributable premature mortality is determined by GEOS-Chem modeled fractional contributions of export-driven $\mathrm{NH}_{3}$ emissions to total $\mathrm{PM}_{2.5}$ and the calibrated high-resolution $\mathrm{PM}_{2.5}$ data from GBD 201326. Premature mortality on a resolution of $0.1^{\circ} \times 0.1^{\circ}$ is estimated following the methods of the GBD study to estimate the premature deaths from ambient $\mathrm{PM}_{2.5}$ exposure (see "Methods"). Maps were created by using the NCAR Command Language, version 6.4.0 (NCAR, https://doi.org/10.5065/D6WD3XH5). 
export-related livestock production is 36 thousand deaths, and by export-related crop production is 25 thousand deaths. It suggests that $\mathrm{NH}_{3}$ emissions from trade-related livestock production need more strict control due to its higher overlap with residential regions that are populated and have high emissions of $\mathrm{NO}_{x}$ and $\mathrm{SO}_{2}$, particularly over Mainland China and India (Fig. 2). Supplementary Table 3 shows the top 20 trading pairs of sectoral $\mathrm{NH}_{3}$ trade-related health impacts. We found that Mainland China and India suffer substantial health costs via exporting to developed countries. Moreover, there are large variations in the health effects across different regions of each country due to differences in local $\mathrm{PM}_{2.5}$ levels, population densities and agricultural production activities. For example, $73 \%$ (90\%) of health burden from crop sector (livestock sector) in the USA was found on eastern USA (east of $95^{\circ} \mathrm{W}$ ), and $58 \%$ (78\%) of health burden from crop sector (livestock sector) was concentrated in northern India (north of $24^{\circ} \mathrm{N}$ ). Northern China (north of $30^{\circ} \mathrm{N}$ ) is the hotspot of China's related premature deaths, accounting for about $70 \%$ from the crop sector or livestock sector. These results suggest that the health effects related to the livestock sector are more likely to be regionally concentrated, so place-based strategies on regional emission reduction are particularly needed. Regions need to consider more strict regulations on emissions from the sector that causes larger health burdens.

Overall, health impacts related to export-related emissions from major developing countries such as China, India, Pakistan, and Southeastern Asian countries account for $\sim 70 \%$ of worldwide premature mortality. This highlights the huge potentials and benefits of reducing $\mathrm{NH}_{3}$ emissions in international trade.

Structure of $\mathrm{NH}_{3}$ trade-related health-effect network. Using embodied emissions in export and import, we decompose the country-level health burdens into bilateral health effects and construct an interconnected network of $\mathrm{NH}_{3}$ trade-related health impacts. Unlike previous studies ${ }^{14}$ that explore international trade relationships from the perspective of emissions only, here we conduct a more comprehensive analysis by linking the emission-induced health effects to trade networks. The healtheffect network is not only determined by export-related emissions but also by local air pollution levels and population densities. Identifying this network structure can help trace the origins of the health impacts and pinpoint effective mitigation strategies of $\mathrm{NH}_{3}$ emissions embodied in international trade.

Figure 3 shows that the global health-effect network is characterized by three trading communities. Community 1-EUCA mainly consists of countries in Europe and Central Asia. Community 2-SWA-AF-SA is formed by countries in South and West Asia, Africa, and South America, while Community 3-ESANA-OA is dominated by East and Southeast Asia, North America, and Oceania. Countries within each community are closely integrated and can be extrinsically motivated to cooperate on emission reduction. We employ the Girvan-Newman community detection algorithm ${ }^{29}$ to reveal the clustering features (see "Methods"). The community structure is mainly regulated by geographic proximity, which is the pivotal determinant of international agricultural trade, partly due to the low valueadded but high transportation and storage costs of agricultural products. Overall, $64 \%$ of the total trade-related health effects are attributed to intracommunity flows, coinciding with the high regional integration of agricultural goods trade. More specifically, in all communities, the major portion of export-related health effects are attributed to themselves. The import-related health effects of all communities are also sourced from themselves, except for Community 2-SWA-AF-SA. This regional amalgamation implies that the priority of reducing trade-induced $\mathrm{NH}_{3}$ emissions needs to be given to the mitigation within each community. Despite the common feature in clustering, the roles of the three communities vary in the network. More than $75 \%$ of import-related health effects in Community 2-SWA-AF-SA are from other communities, highlighting its role as an importer of agricultural products. On the other hand, only $28 \%$ of exportrelated health effects in Community 3-ESA-NA-OA are induced by other communities despite that it has the greatest importrelated health effects. This indicates the high mitigation responsibilities of Community 3-ESA-NA-OA are largely attributed to itself, while Community 2-SWA-AF-SA needs to undertake more obligations than what its direct emissions suggest.

In each community, some hub countries connect the loosely linked economies. To evaluate the network's heterogeneity, we examine degree distributions of the network (Supplementary Fig. 2). The network approximately follows a scale-free network ${ }^{30}$ that is stable against random failures but vulnerable to targeted attacks $^{31}$ (see "Methods"). This means effectively mitigating the health effects from trade-related $\mathrm{NH}_{3}$ emissions requires more effort given to the hub economies because changing their trade practices and emission intensities per gross output will generate profound influences on the whole network.

We further exploit network indicators to identify hub economies (see "Methods"). Mainland China, USA, India, and Germany play the most vital roles of main bridges in their communities, respectively (Supplementary Fig. 3c, d), based on the betweenness centrality that assesses node connectivity and intermediacy ${ }^{32}$. Although the number of importing sources (indegree) of major European economies in Community 1-EU-CA are greater than Japan and Hong Kong, their import-related health effects are noticeably smaller (Supplementary Fig. 3a). By contrast, China and India, the leading countries in Community 3 ESA-NA-OA and Community 2-SWA-AF-SA, bear more than $50 \%$ of aggregated export-related health loss (Supplementary Fig. 3b) and share a similar number of exporting destinations (out-degree). As reflected by eigenvector centrality, Japan and Hong Kong also act as important bridges since they are major importers of agricultural products in their communities (Supplementary Fig. 3e). Lastly, small-degree economies tend to trade with hub economies, as indicated by Supplementary Fig. 3f. It suggests that the health-effect network displays high levels of regional integration despite some heterogeneity. This regionally clustered trade network offers potential solutions for $\mathrm{NH}_{3}$ emission reduction through regional cooperation within each community.

Implications for $\mathrm{NH}_{3}$ emission mitigation and international cooperation. Both regional and global perspectives are essential to developing $\mathrm{NH}_{3}$ emission reduction strategies. The identification of regional communities from the network analysis provides a new lens on $\mathrm{NH}_{3}$ emission control. Analogous to "climate clubs" proposed by Nordhaus ${ }^{33}$, countries identified in the same community by our methods are tightly connected in the healtheffect network, so they are strongly incentivized to form a mitigation club of $\mathrm{NH}_{3}$ emissions, i.e., club members are expected to promote technological advancements and trade structure adjustments to obtain overall $\mathrm{NH}_{3}$ emission reductions within each community. The integrated structure also suggests that fewer trade barriers exist within the community and that member states are more likely to collaborate. Importing countries will directly benefit from the adjustments due to less pollution spillover. Countries with excessive exports will reduce health damages but also sacrifice their economic gains from exports. To align their incentives, intergovernmental coordination, as highlighted by the 

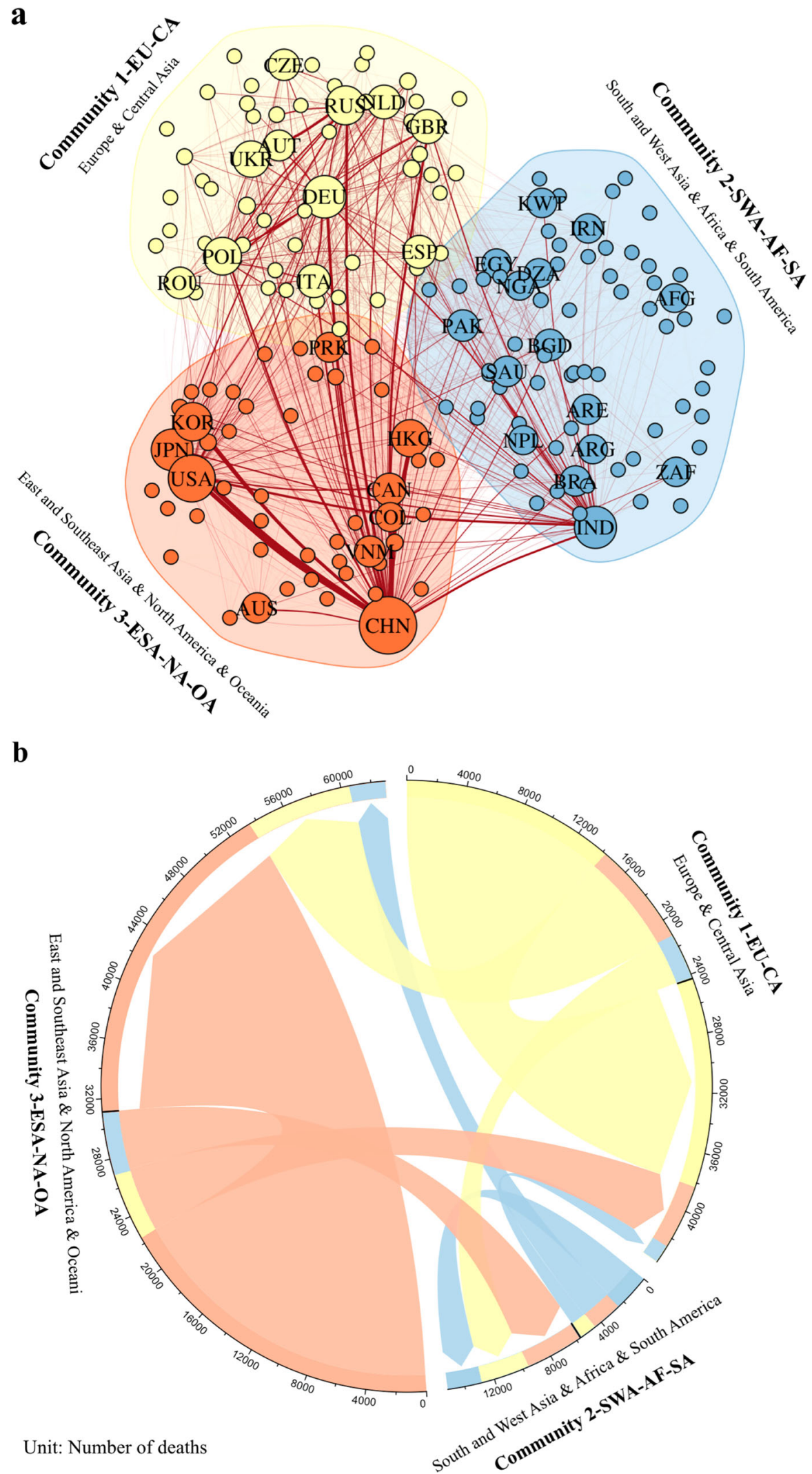

Fig. 3 Regional communities of $\mathbf{N H}_{\mathbf{3}}$ trade-related health-effect network. a The partitions of communities. Along with each community, the major hub economies are also indicated. The size of a circle represents the relative trade-related health loss. The width of a connecting line between two circles represents the relative health loss attributed to the trade between the two nodes. $\mathbf{b}$ The intracommunity and intercommunity health-effect flows (number of deaths). Community 1-EU-CA (in yellow) is mainly formed by countries in Europe and Central Asia; Community 2-SWA-AF-SA (in blue) consists of countries in South and West Asia, Africa, and South America; Community 3-ESA-NA-OA (in orange) is dominated by countries in East and Southeast Asia, North America and Oceania. The width of the connecting line represents trade-related health loss. The three-letter country abbreviations inserted in the plot are detailed in Supplementary Data 6. Supplementary Fig. 6 shows the geographical distributions of communities. 


\begin{tabular}{|c|c|c|c|}
\hline Regions & $\begin{array}{l}\text { Community } \\
\text { 1-EU-CA }\end{array}$ & $\begin{array}{l}\text { Community } \\
\text { 2-SWA-AF-SA }\end{array}$ & $\begin{array}{l}\text { Community } \\
\text { 3-ESA-NA-OA }\end{array}$ \\
\hline Baseline $\mathrm{NH}_{3}$ emissions & 8700 & 16,600 & 27,100 \\
\hline \multicolumn{4}{|l|}{ Trade-side strategies } \\
\hline \multicolumn{4}{|l|}{ Production-side strategies } \\
\hline Reducing overuse of $\mathrm{N}$ in grain crops & 550 & 1400 & 2500 \\
\hline Deep fertilizer placement & 1700 & 3800 & 6500 \\
\hline Use enhanced-efficiency fertilizers & 1600 & 3700 & 6300 \\
\hline Moderate manure management improvements & 1400 & 1600 & 2400 \\
\hline Drastic manure management improvements & 2700 & 3200 & 4800 \\
\hline Maximum technically feasible reductions (MTFR) & 2800 & 7100 & 15,200 \\
\hline
\end{tabular}

Interconvention Nitrogen Coordination Mechanism ${ }^{34}$, is a requisite for member countries to form a mitigation "club." Members in violation of club rules will be penalized by uniformly punitive tariffs and other multilateral policies. As long as the mutual gains from emission reduction are sufficiently large, countries are motivated to obey club rules ${ }^{33}$. Here we propose $\mathrm{NH}_{3}$ reduction scenarios through trade structure adjustments and technological advancements within the regionally tradedependent communities (Table 1).

Trade structure adjustments include the import substitution scenario and export transfer scenario. In the scenario of import substitution, we consider replacing imports of agricultural goods with domestic production if the emission intensity of the exporter is higher than the importer. Larger emission reductions will be achieved if production is allowed to be transferred to a third country with emission intensities even lower than both the original exporter and importer. The export transfer scenario thus will minimize the agricultural trade-related $\mathrm{NH}_{3}$ emissions by taking total exports as given and reorganizing the production structure of exported goods. Nevertheless, complete substitution is unrealistic. Countries are unable to expand their agricultural production beyond their total capacity. We impose this constraint with their potential capacity in agricultural production, measured by the area of arable land multiplied by the value of agricultural products per unit area. We also limit trade substitution to the countries with similar annual average temperature and precipitation (see "Methods").

This scenario analysis of import substitution and export transfer is applied to countries within each community. Table 1 shows that import substitution has modest effects on emission reduction, but the export transfer displays considerable potentials to reduce $\mathrm{NH}_{3}$ emissions. Especially, export transfer in both Community 1-EU-CA could reduce $\mathrm{NH}_{3}$ emissions by $750 \mathrm{Gg}$. With $\mathrm{NH}_{3}$ emission reduction of over $100 \mathrm{Gg}$, Belarus, Germany, France, and Spain are the most benefited countries in Community 1-EU-CA (Supplementary Data 4). In Community 3-ESA-NA$\mathrm{OA}, \mathrm{NH}_{3}$ emissions are reduced by $230 \mathrm{Gg}$ in Mainland China, followed by Myanmar ( $80 \mathrm{Gg})$, Mexico $(70 \mathrm{Gg})$, and Chile $(60 \mathrm{Gg})$. The most benefited countries in Community 2-SWA-
AF-SA are Ethiopia (150 Gg), Pakistan (100 Gg), and Argentina $(80 \mathrm{Gg})$. The contribution of import substitution to $\mathrm{NH}_{3}$ reduction is largest in Community 1-EU-CA (210 Gg) (Supplementary Data 5). This estimated $\mathrm{NH}_{3}$ emission reduction demonstrates that regional efforts within each community through trade structure adjustments have substantial potential in $\mathrm{NH}_{3}$ emission mitigation even under current production efficiency. The distinction between the scenarios of import substitution and export transfer further implies that effective trade adjustments to reduce $\mathrm{NH}_{3}$ emissions call for communitylevel multilateral cooperation instead of unilateral trade substitution.

Technological advancement is expected to be the most effective way to mitigate $\mathrm{NH}_{3}$ emissions ${ }^{1,35}$. Here the regionally integrated health-effect network incentivizes countries within the same community to foster technological advancements in reducing $\mathrm{NH}_{3}$ emissions. We estimate potential global $\mathrm{NH}_{3}$ emission reduction achieved through the production side and consumption side (see "Methods"). The effectiveness of food production and consumption strategies in reducing $\mathrm{NH}_{3}$ emissions are summarized in Table 1. In terms of production-side mitigation, we consider three improved management of agricultural nitrogen from crop production, and two scenarios from livestock production. These technological advancements display huge potentials to reduce $\mathrm{NH}_{3}$ emissions in Table 1. Especially, strict mitigations (e.g., deep fertilizer placement or use of enhancedefficiency fertilizers) for crop production show substantial potentials for Community 2-SWA-AF-SA and Community 3ESA-NA-OA where $\mathrm{NH}_{3}$ emissions are high. For comparison, we also show the maximum technically feasible reduction (MTFR) scenario by the year 2050 calculated from the GAINS (Greenhouse gas-Air pollution Interactions and Synergies) model ${ }^{36}$. The MTFR scenario implements the best available mitigation technology that varies regionally. The strictest $\mathrm{NH}_{3}$ emission reduction (e.g., deep fertilizer placement and drastic manure management) we propose is comparable with the $\mathrm{NH}_{3}$ emission reduction under the MTFR scenario by the year 2050 .

In terms of consumption-side mitigation, we consider dietary adjustment scenarios in Table 1. Given current food production 
and consumption practices worldwide, different regions should prioritize different strategies. USA and Europe, which already have developed modern agriculture with reasonably good nitrogen management practices, could focus on consumptionside strategies. Developing countries in Community 2-SWA-AFSA and Community 3-ESA-NA-OA, such as India and Mainland China need to dedicate themselves to both production-side and consumption-side strategies.

To further estimate the health benefits of $\mathrm{NH}_{3}$ emission reductions under different scenarios, we select three scenarios (i.e., export transfer, reducing overuse of $\mathrm{N}$ in grain crops, and reducing beef consumption by 20\%) for quantifying the associated $\mathrm{PM}_{2.5}$ changes and related health effects by conducting GEOS-Chem simulations. Under each scenario, we applied the reduction ratio to spatiotemporally-changed $\mathrm{NH}_{3}$ emissions for each country. It is also assumed that population densities and baseline mortality in IER functions are the same as in the year 2012. The estimated health benefits under these three scenarios are listed in Supplementary Table 4. Overall, we find that the $\mathrm{NH}_{3}$ emission reduction by trade-side strategies is comparable to the reduction by consumption-side strategies, while production-side strategies tend to be the dominant driver for future $\mathrm{NH}_{3}$ emission reduction.

Given the absence of $\mathrm{NH}_{3}$ emission regulations, the Fourth United Nations Environment Assembly in March 2019 approved the first-ever global resolution on nitrogen ${ }^{37}$, and intended to establish an intergovernmental coordination mechanism on nitrogen policies. However, it is not yet clear how long it will take for countries to reach a binding agreement and how ambitious the mitigation target will be. The regional communities identified by our network analyses and the community-based $\mathrm{NH}_{3}$ emission controls proposed in this research will fill this gap. Countries in the same community are strongly incentivized to form an $\mathrm{NH}_{3}$ mitigation club to promote technological advancements and trade structure adjustments to obtain overall $\mathrm{NH}_{3}$ emission reduction within each community.

\section{Discussion}

In summary, interventions on interregional and intraregional trade structures in each community contribute to significant $\mathrm{NH}_{3}$ emission reduction, due to huge health impacts from tradeinduced global agricultural $\mathrm{NH}_{3}$ emissions. Countries are incentivized to optimize trade structure and consume fewer emissionintensive agricultural products, while this could, in turn, prompt upstream suppliers to adopt environmentally benign agricultural technologies and minimize the negative environmental outcomes of agricultural production. Our results demonstrate that there are appreciable potentials in reducing $\mathrm{NH}_{3}$ emissions through effective cooperation within the regional trade-dependent community. Naturally, the proposed solution in this study is also applicable to the mitigation of agricultural greenhouse gas emissions.

Some limitations exist in this study, i.e. uncertainties in $\mathrm{NH}_{3}$ emission inventory, de-coupled approach for reducing $\mathrm{NH}_{3}$ from crop and livestock sectors, and assumptions with trade scenarios. For $\mathrm{NH}_{3}$ emission inventory, the low resolution of agricultural sectors in many developing countries could cause uncertainty to the global MRIO analysis. More efforts are required to compile reliable and high-resolution $\mathrm{NH}_{3}$ emission inventories associated with disaggregated agricultural sectors.

For our evaluation of ammonia emission mitigation potential, we have treated crop and livestock sectors as separate and independent sectoral sources. In reality, they are interconnected subcomponents of agricultural systems ${ }^{38}$. In detail, our analyses of the effects of manure deep placement (Table 1) assume that abundant cropland exists for manure application and that crop farmers will reduce the application of inorganic nitrogenous fertilizers accordingly to avoid excess $\mathrm{N}$ use. These assumptions create real-world logistical challenges. For example, animal production has become more concentrated in the USA. In many states, the amount of manure excreted has exceeded local assimilative cropland capacity, demanding off-farm export ${ }^{39}$. Farmers may not reduce inorganic fertilizer $\mathrm{N}$ use without governmental education efforts or economic/policy mechanisms that avoid excess $\mathrm{N}$ use $\mathrm{e}^{40}$. In addition, manure acidification, although reduces $\mathrm{NH}_{3}$ emissions during storage, may result in a larger amount of $\mathrm{N}$ susceptible for $\mathrm{NH}_{3}$ losses during the disposal stage. Thus, future work using integrated models that represent $\mathrm{N}$ flows in both crop and livestock sectors and their interactions may provide a more precise estimation of $\mathrm{NH}_{3}$ emission responses to sectoral strategies.

For trade reduction scenarios, other factors, such as political interests, also have determinant effects on international trade. However, in the past decades, countries have resolved many transnational conflicts and spillovers through international agreements. For example, the international collaboration on carbon emissions moves fast, which includes some trade-related measures such as imposing the carbon tax. The evidence of mitigation potential comes first, and then we can look forward to the effect. Therefore, we believe that the trade-side strategies, as well as other joined-up efforts proposed in the Interconvention Nitrogen Coordination Mechanism ${ }^{34}$, could be of interest for future international cooperation.

\section{Methods}

$\mathbf{N H}_{3}$ emissions. Agricultural sources of $\mathrm{NH}_{3}$ emissions refer to manure management, direct and indirect soil emissions, manure in pasture/range/paddock, and agricultural waste burning. The estimation of agricultural $\mathrm{NH}_{3}$ emissions at the country level is extremely challenging, due to the fact that a large amount of activity-level data and emission factors are hard to obtain. The EDGAR v4.3.2 emission database ${ }^{27}$ from Joint Research Centre, European Commission, has updated the bottom-up inventories of $\mathrm{NH}_{3}$ emissions of nations to the year of 2012, which make it possible for a more systematic study on consumption-based accountings of global $\mathrm{NH}_{3}$ emissions.

Global MRIO model. The global MRIO tables covering multiple regions of the world have been prepared by multiple organizations. Among these tables, the MRIO tables from the Eora database cover the most regions ${ }^{41,42}$, which have been widely used to analyze the embodied resource and environmental elements in international trade ${ }^{43-45}$. In this study, the Eora database is adopted to build the global MRIO table for 2012.

The global MRIO model, incorporating direct emission inventories, reveals the $\mathrm{NH}_{3}$ emissions induced by final demand and international trade. MRIO can trace the emissions back to the original source that produced the emissions even if products were intermediate constituents in a multiregional supply chain. To perform the MRIO modeling, we should extract the direct emission data that are related to economic activities and reallocate these data to each industrial sector of different economies. The resulting emissions at the sectorial level are used in the MRIO model to link the emissions to consumption and trade. Assume that the number of sectors of country $s$ is $k_{s}$, the number of countries is $n$, and denote $N=\sum_{s=1}^{n} k_{s}$. According to the balance of the global MRIO model, the basic linear equation can be expressed as

$$
\mathbf{X}=\mathrm{AX}+\mathbf{F}
$$

where $\mathbf{X}$ is the $N \times 1$ gross-output vector, $\mathrm{A}$ is the $N \times N$ technical coefficien matrix, and $\mathbf{F}$ stands for the $N \times 1$ final-consumption vector.

After that, the Leontief inverse matrix can be obtained from Eq. (1):

$$
L=(I-A)^{-1}
$$

Here, $(I-A)^{-1}$ is the Leontief inverse matrix, which shows the total production of each sector required to satisfy the final demand in the region; $I$ is the identity matrix. $D$ refers to the $N \times N$ matrix diagonalized from the $N \times 1$ vector of sectorial $\mathrm{NH}_{3}$ emission intensities ( $\mathrm{NH}_{3}$ emissions per output). Since we are interested in the embodied agricultural $\mathrm{NH}_{3}$ emissions in global trade, the emission intensities of nonagricultural sectors are assigned to be zero. The global $\mathrm{NH}_{3}$ emission flow matrix can be acquired by

$$
C=D L \hat{F}
$$

where $\hat{F}$ is a $N \times N$ matrix diagonalized from the vector $\mathbf{F}$. The $\mathrm{NH}_{3}$ emission flow 
matrix $C$ can be written as the following block matrix

$$
\mathrm{C}=\left[\begin{array}{ccccc}
\mathrm{C}_{11} & \cdots & \mathrm{C}_{1 \mathrm{t}} & \cdots & \mathrm{C}_{1 \mathrm{n}} \\
\vdots & \ddots & & \ddots & \\
\mathrm{C}_{\mathrm{s} 1} & & \mathrm{C}_{\mathrm{st}} & & \mathrm{C}_{\mathrm{sn}} \\
\vdots & \ddots & & \ddots & \\
\mathrm{C}_{\mathrm{n} 1} & \cdots & \mathrm{C}_{\mathrm{nt}} & \cdots & \mathrm{C}_{\mathrm{nn}}
\end{array}\right]
$$

where $C_{s t}$ is a $k_{s} \times k_{t}$ matrix. When $s \neq t, C_{s t}$ denotes the emissions produced in region $s$ that are related to the final consumption of region $t$. When $s=t, C_{s t}$ represents emissions related to final consumption produced locally. Let $T_{s t}$ refer to the sum of each element $C_{s t}^{(i j)}$ in $C_{s t}$

$$
T_{s t}=\sum_{i=1}^{k_{s}} \sum_{j=1}^{k_{t}} C_{s t}^{(i j)}
$$

$T_{s t}$ is a scalar that represents the total embodied agricultural emissions that are produced in region $s$ and related to the final consumption of region $t$.

Based on the $\mathrm{NH}_{3}$ flows matrix, two key indicators that reflect the impacts of international trade on $\mathrm{NH}_{3}$ emissions can be deduced. The $\mathrm{NH}_{3}$ emissions embodied in international import and export are expressed as

$$
\begin{gathered}
\mathrm{EEI}^{s}=\sum_{t=1, t \neq s}^{n} T_{t s} \\
\mathrm{EEE}^{s}=\sum_{t=1, t \neq s}^{n} T_{s t} \\
\mathrm{EEB}^{s}=\mathrm{EEI}^{s}-\mathrm{EEE}^{s}
\end{gathered}
$$

where $\mathrm{EEI}^{s}$ is the total emissions in other regions related to consumption in region $s$, while $\mathrm{EEE}^{s}$ is the total emissions in region $s$ related to final consumption in other regions. The embodied $\mathrm{NH}_{3}$ emissions in international trade balance (EEB) can be obtained as the difference of import (EEI) and export (EEE). The EEB is also equal to the difference between the $\mathrm{CBE}$ emissions and its $\mathrm{PBE}$ emissions of a region. A positive value of EEB means that a region's CBE emissions are larger than its PBE emissions.

Adjustment to sectors and regions. The 189 countries/regions in the original MRIO table are merged with the EDGAR database. Serbia and Montenegro are merged into one country. Seven regions cannot be merged with the EDGAR database and thereby are dropped (Andorra, Former USSR, Gaza Strip, Liechtenstein, Monaco, San Marino, South Sudan). Finally, we have 181 economies (Supplementary Data 6) and 14,839 economy-sector pairs.

In the Full Eora database, most countries have more than two agricultural sectors. Crop and livestock sectors differ noticeably in their $\mathrm{NH}_{3}$ emission intensities (emissions per output). Therefore, we allocate $\mathrm{NH}_{3}$ emissions to crop and livestock sectors, respectively. More specifically, for each region, we assume the same emission intensity (emission per output) for different crop sectors, and allocate emissions to the detailed sectors based on their outputs. Similarly, we assume the same emission intensity for different livestock sectors and allocate emissions according to their outputs.

Furthermore, input-output analysis is susceptible to aggregation errors due to coarse sector classifications. For example, the ratio of export-related emissions to PBEs in Ethiopia is more than 90\%, because it exports the agricultural products with smaller embodied emissions (such as coffee) ${ }^{14}$. Even though we use the Full Eora MRIO database that covers a comprehensive set of sectors for developed countries, some developing countries are only recorded in 26 sectors. To alleviate potential aggregation biases, we use product-level trade information from the United Nations Comtrade Database and follow Oita et al. ${ }^{14}$ to manually correct misallocation for countries susceptible to aggregation errors. Supplementary Table 5 shows the countries and exported commodities to be adjusted for aggregation errors. Due to missing data in the Comtrade database, we do not adjust exports of five small countries (Bermuda, Brunei Darussalam, Cape Verde, Cayman Islands, Netherlands Antilles) that are considered by Oita et al. ${ }^{14}$ We adjust exports of another country (Papua New Guinea) that is also susceptible to aggregation errors due to large export of palm oil, coffee, and cocoa beans. The embodied emissions calculated with the Eora-26 MRIO database, which has coarser sector classifications, are quite close to the results by the Full Eora database with adjustment to aggregation errors (Supplementary Fig. 4). This suggests that potential aggregation errors have a limited effect on the calculations and are unlikely to bias the analysis.

Complex network model. We use complex network indicators and the community detection method to analyze the global $\mathrm{NH}_{3}$ trade-related health-effect network characteristics.

(1) Degree and degree distribution: in the health-effect network, definitions of out-degree and in-degree are analogous to those in trade network ${ }^{46-48}$. Out- degree is the number of economies to which a given economy bears health loss for exporting goods, and in-degree is the number of economies that a given economy is transferring health loss to by importing goods from them. The two indicators measure the extensive margin of the economy involved in international trade and are defined as

$$
k_{i}^{\text {out }}=\sum_{j=1(i \neq j)}^{n} a_{i j}, k_{i}^{\text {in }}=\sum_{j=1(i \neq j)}^{n} a_{j i}
$$

where $a_{i j}$ is a dummy variable indicating whether health effects are flowing from economy $i$ to economy $j, n$ is the total number of economies (181 in the health-effect network), $k_{i}^{\text {out }}$ and $k_{i}^{\text {in }}$ represent the out-degree and indegree, respectively.

To further analyze the heterogeneity among the 181 economies, we calculate the probability distribution of degree $k$ as $p(k)=n_{k} / n$, where $n_{k}$ is the number of economies that have the same degree $k$. The network can be characterized as a scale-free network if its degree distribution is well fitted by a power-law distribution, i.e., $p(k) \propto k^{-\lambda}$. A scale-free network implies the coexistence of a large number of nodes in the periphery that are loosely connected with others and a very few hub nodes that play central roles in connecting other nodes.

If we consider the weighted health-effect network, links connecting any two economies are not regarded as binary indicators but weighted in proportion to the health-effect flows between them. Just analogous to out-degree and indegree, out-strength and in-strength can be obtained by replacing $a_{i j}$ with $q_{i j}$, which indicates the volume of health effects transferred from $i$ to $j$ :

$$
s_{i}^{\text {out }}=\sum_{j=1(i \neq j)}^{n} q_{i j}, s_{i}^{\text {in }}=\sum_{j=1(i \neq j)}^{n} q_{j i}
$$

(2) Betweenness centrality: betweenness centrality characterizes the connectivity and intermediality of a network and reflects the importance of a given node as the role of bridging other nodes by calculating the number of shortest paths that go through it:

$$
b_{k}=\sum_{i=1}^{n} \sum_{j=1}^{n} \sigma_{i j}(k) / \sigma_{i j}
$$

where $\sigma_{i j}$ is the number of shortest paths between economy $i$ and economy $j$ $\sigma_{i j}(k)$ is the number of shortest paths between $i$ and $j$ that pass through economy $k, b_{k}$ is the betweenness centrality of economy $k$. This measure indicates if economy $k$ is on the shortest path between $i$ and $j$, then it counts towards the betweenness centrality of economy $k$. In the health-effect network, an economy with high betweenness centrality implies its crucial bridging roles in transferring or receiving health effects.

For the weighted health-effect network, the path length from economy $i$ to economy $j$ is defined by the number of bilateral flows of health effects $q_{i j}$, with which we likewise obtain the weighted betweenness centrality.

(3) Eigenvector centrality: another prevalent centrality measure is the eigenvector centrality, which evaluates the importance of a node based on its neighboring nodes. The intuition behind this is that a node should have high centrality if it is connected with many other nodes that also have high eigenvector centrality. Eigenvector centrality is defined as:

$$
\mathbf{v}_{\mathbf{i}}=\lambda^{-1} \sum_{j=1}^{n} a_{i j} \mathbf{v}_{\mathbf{j}}
$$

where $\lambda$ and $\mathbf{v}_{\mathbf{j}}$ are the largest eigenvalue and the corresponding eigenvector.

(4) The weighted average of nearest-neighbor degree: a similar hybrid network is a network in which nodes tend to be connected with other nodes of similar degree. To assess this tendency, we calculate the weighted neighboring degree of node $i$ :

$$
\omega_{i}=\sum_{j=1}^{v(i)}\left(q_{i j}+q_{j i}\right)\left(k_{j}^{\text {out }}+k_{j}^{\text {in }}\right) /\left(s_{i}^{\text {out }}+s_{i}^{\text {in }}\right)
$$

where $v(i)$ is the number of the neighboring nodes of economy $i$. Given that the degree of economy $i$ is $k$, the average neighboring degree of all the nodes with degree $k$ is defined as:

$$
\omega(k)=\sum_{i \in\left\{j \mid k_{j}^{\text {out }}+k_{j}^{\text {in }}=k\right\}}^{n_{k}} \omega_{i} / n_{k}
$$

The network is a similar hybrid network if and only if $\omega(k)$ is monotonically increasing in $k$.

(5) Community detection: in order to better visualize the health-effect network, it is useful to partition the complex network, which consists of 181 nodes and more than 30,000 edges, into several submodules or communities, within which the nodes are densely linked but sparsely connected with the nodes in other communities. We apply the modularity maximization method introduced by Girvan and Newman ${ }^{29}$ to find the community partition of the health-effect network. The modularity of partition compares the compactness of the links inside communities with the links between communities. A higher value of modularity suggests better quality of 
community partition. The modularity $Q$ in our network is defined by:

$$
Q=\frac{1}{2 m} \sum_{i=1}^{n} \sum_{j=1}^{n}\left[w_{i j}-\frac{p_{i} p_{j}}{2 m}\right] \delta\left(c_{i}, c_{j}\right)
$$

where $w_{i j}=q_{i j}+q_{j i}$ is the amount of health effects connection between economy $i$ and economy $j, p_{i}=\sum_{j=1}^{n} w_{i j}$ is the sum of health effects attached to economy $i, c_{i}$ is the community to which economy $i$ is assigned, $\delta\left(c_{i}, c_{j}\right)$ is an indicator function which equals to 1 if $c_{i}=c_{j}$ and 0 otherwise, and $m=\sum_{i=1}^{n} \sum_{j=1}^{n} w_{i j} / 2$. We use this algorithm to implement the method and extract community structures of the network.

Chemical transport model. The GEOS-Chem is a global three-dimensional CTM of the atmospheric compositions (version 12.0.0, http://www.geos-chem.org), and includes detailed ozone- $\mathrm{NO}_{x}-\mathrm{VOC}$-aerosol chemistry ${ }^{49}$. The model was run at a horizontal resolution of $2^{\circ}$ latitude by $2.5^{\circ}$ longitude driven by the NASA ModernEra Retrospective Analysis for Research and Applications, Version 2 (MERRA-2) meteorological fields. In GEOS-Chem simulations, $\mathrm{NH}_{3}$ emissions from anthropogenic sources were from EDGAR v4.3.2 for 2012, and emissions from soil, vegetation, and the oceans were from the Global Emissions Inventory Activity inventory ${ }^{50}$. Other global anthropogenic emissions of $\mathrm{NO}_{x}, \mathrm{SO}_{2}, \mathrm{CO}$, black carbon (BC), and organic carbon (OC) from EDGAR v4.3.2 and speciated volatile organic compounds emissions from the RETRO, overwritten by the default regional emissions, were adopted. Other natural emissions follow the configuration of Li et al. ${ }^{51}$.

A baseline simulation was conducted driven by global anthropogenic and natural emissions described above. To quantify the impacts of export-related agricultural $\mathrm{NH}_{3}$ emissions on particulate air pollution, sensitivity simulations with deducted $\mathrm{NH}_{3}$ emissions embodied in international trade for 181 countries were also performed. For each country, the trade-related fraction of $\mathrm{NH}_{3}$ emissions is assumed uniform, and this method has been applied widely in the previous studies ${ }^{21,22,52}$. The fractional contributions of export-related $\mathrm{NH}_{3}$ emissions to $\mathrm{PM}_{2.5}$ were determined on a $2^{\circ}$ latitude by $2.5^{\circ}$ longitude grid, due to model resolution. Then, these spatially varying fractions were multiplied by the $0.1^{\circ} \times 0.1^{\circ}$ global $\mathrm{PM}_{25}$ concentrations from GBD $2013^{28}$ to get estimated $\mathrm{PM}_{25}$ concentrations induced by export-related $\mathrm{NH}_{3}$ emissions. All the simulations were conducted from January to December 2012 after a 6-month model initialization (July-December 2011).

GEOS-Chem aerosol simulations have been extensively evaluated using groundbased measurements worldwide ${ }^{2,11,22,53-57}$, including the USA, Europe, China, and India. These previous studies have shown that the GEOS-Chem model can reasonably the response of $\mathrm{PM}_{2.5}$ formation to emission changes as well as the observed concentrations of $\mathrm{PM}_{2.5}$ components. For example, Zhang et al. ${ }^{22}$ reported that major $\mathrm{PM}_{2.5}$ components simulated by GEOS-Chem have an $R^{2}$ of $0.52 \sim 0.78$ when compared with those observed values over the US, Europe, and East Asia, while it tends to underestimate (overestimate) BC (nitrate). The high bias of nitrate and low bias of $\mathrm{BC}$ are the common issues in the GEOS-Chem model ${ }^{11,58}$. It means that further improvement of the model's capability in capturing the dynamics of the sulfate-nitrate-ammonium aerosol systems is needed. Here we used GBD-based $\mathrm{PM}_{2.5}$ concentrations in 2012 to validate the model-simulated $\mathrm{PM}_{2.5}$ concentrations (Supplementary Fig. 5). The simulated and GBD-based $\mathrm{PM}_{2.5}$ concentrations (with a resolution of $0.1^{\circ} \times 0.1^{\circ}$ ) have a correlation coefficient of 0.6 and normalized mean bias of $-0.5 \%$. These two datasets compare reasonably well for most regions, including high values of over $80 \mu \mathrm{g} \mathrm{m}^{-3}$ over eastern China and northern India, higher values in the eastern US than the western US, and high values of about $35 \mu \mathrm{g} \mathrm{m}^{-3}$ over some European areas.

Assessment of health impacts. Methods of the GBD study ${ }^{28}$ are followed to estimate the premature deaths from ambient $\mathrm{PM}_{2.5}$ exposure. Here the impacts due to the four leading causes of death: ischemic heart disease, chronic obstructive pulmonary disease, cerebrovascular disease, and lung cancer are considered. In 2012 , these four major diseases together accounted for 18.4 million deaths $(\sim 35 \%$ of all-cause mortality). We estimate 3.54 million premature deaths attributable to $\mathrm{PM}_{2.5}$ in 2012 , which agrees well with some previous studies such as the GBD 59 (3.44 million deaths) and Zhang et al..$^{22}$ (3.45 million deaths).

We applied IER functions developed by Burnett et al..$^{59}$, which incorporated data from cohort studies of ambient $\mathrm{PM}_{2.5}$ pollution, household air pollution, and active and passive tobacco smoke, to fit the concentration-response relationship throughout the full distribution of ambient $\mathrm{PM}_{2.5}$ concentrations. Thus, high $\mathrm{PM}_{2.5}$ concentrations similar to those observed in China and India can be also accounted for. For each disease, the relative risk for mortality estimations for the all-age group was calculated as the following equation:

$$
\begin{aligned}
\mathrm{RR}(C) & =1+\alpha\left\{1-\exp \left[-\gamma\left(C-C_{0}\right)^{\delta}\right]\right\} \text { for } C>C_{0} \\
\mathrm{RR} & =1 \text { for } C \leq C_{0}
\end{aligned}
$$

where $C$ represents the annual mean $\mathrm{PM}_{2.5}$ concentration (on a $0.1^{\circ} \times 0.1^{\circ}$ grid) in 2012 , which was exponentially extrapolated from data for 2010 based on the GBD study by Brauer et al. ${ }^{28}$. The calibrated GBD $\mathrm{PM}_{2.5}$ data were estimated by a combination of satellite-based estimates, chemical transport model simulations, and ground measurements; $C_{0}$ is the counterfactual concentration, representing a theoretical minimum-risk concentration above which there is evidence indicating health benefits of $\mathrm{PM}_{2.5}$ exposure reductions (range: $5.8-8.8 \mu \mathrm{g} \mathrm{m}^{-3}$ ); and $\alpha, \gamma$, and $\delta$ are parameters used to determine the overall shape of the concentration-response relationship, which are obtained from Burnett et al. ${ }^{59}$. We reported averaged mortality results using 1000 sets of coefficients and exposure-response functions based on Monte Carlo simulations.

The grid-based $\left(0.1^{\circ} \times 0.1^{\circ}\right)$ premature deaths attributed to ambient $\mathrm{PM}_{2.5}$ exposures were then estimated:

$$
\text { Mort }=y_{0} \times \text { pop } \times(1-1 / \text { RR })
$$

where $y_{0}$ is the Country-level baseline mortality for each disease for the all-age group from the Institute for Health Metrics and Evaluation (http:// ghdx.healthdata.org/ihme_data) and pop is the population obtained from the Gridded Population of the World, version 3 at a resolution of $2.5 \mathrm{~min} \times 2.5 \mathrm{~min}$ which was further aggregated to the same resolution of $0.1^{\circ} \times 0.1^{\circ}$. The estimated 2012 population is linearly extrapolated from the 2010 and 2011 values.

Here, we estimated the mortality contribution from export-related agricultural $\mathrm{NH}_{3}$ emissions based on an assumption that the contribution of one source to the disease burden of $\mathrm{PM}_{2.5}$ is directly proportional to its share of $\mathrm{PM}_{2.5}$ concentration The more recent GBD research, GBD MAPS, has demonstrated the scientific basis of such an assumption, which was adopted by early studies, such as another GBD study $^{60}$ and Zhang et al. ${ }^{22}$. For a given country, the premature deaths from its export-related $\mathrm{NH}_{3}$ emissions can be calculated by multiplying its fractional contribution of export-related $\mathrm{NH}_{3}$ emissions to $\mathrm{PM}_{2.5}$ concentration by the total $\mathrm{PM}_{2.5}$ concentration-related mortalities for each $0.1^{\circ} \times 0.1^{\circ}$ grid cell. The fractional contribution of export-related $\mathrm{NH}_{3}$ emissions to $\mathrm{PM}_{2.5}$ was estimated by the GEOS-Chem simulations.

Trade structure adjustment scenarios. Scenario analysis is conducted through import substitution and export transfer within the countries in each community.

Suppose that country $i$ imports $\mathrm{IM}_{i j}$ agricultural products from country $j$, and the $\mathrm{NH}_{3}$ emission intensities of the two countries are $\mathrm{EI}_{i}$ and $\mathrm{EI}_{j}$. If $\mathrm{EI}_{i}<\mathrm{EI}_{i}$, emission reduction can be achieved by country $i$ to substitute the import $\mathrm{IM}_{i j}$ with its own production. Denote the amount substituted as $\mathrm{ST}_{i j}$. For any country $i$, the objective function of import substitution is to maximize the emission reduction, i.e., $\sum_{j=1, j \neq i}^{n}\left(\mathrm{EI}_{j}-\mathrm{EI}_{i}\right) \times \mathrm{ST}_{i j}$. Nevertheless, complete substitution is unrealistic due to constraints in natural resources. Countries are unable to expand their agricultural production beyond their total capacity. We impose this constraint with their potential capacity in agricultural production (denoted as $\mathrm{AC}_{\mathrm{i}}$ ), measured by the area of arable land (in hectare) multiplied by the value of agricultural products per hectare. Furthermore, farm goods produced in different countries are not perfectly substitutable either. To increase the reliability of the counterfactual analysis, we limit trade substitution within countries with annual average temperature (denoted as AVT) and precipitation (denoted as PCP) at similar conditions $\left( \pm 5^{\circ} \mathrm{C}\right.$ for temperature and $\pm 500 \mathrm{~mm}$ for precipitation). Therefore, for country $i$, the objective function of import substitution is:

$$
\begin{gathered}
\max _{\left\{\mathrm{ST}_{i j}\right\}} \sum_{j=1, j \neq i}^{n}\left(\mathrm{EI}_{j}-\mathrm{EI}_{i}\right) \times \mathrm{ST}_{i j} \\
\text { s.t. } \sum_{j=1, j \neq i}^{n} \mathrm{ST}_{i j} \leq \mathrm{AC}_{i} \\
0 \leq \mathrm{ST}_{i j} \leq \mathrm{IM}_{i j} \\
-5 \leq \mathrm{AVT}_{i}-\mathrm{AVT}_{j} \leq 5 \\
-500 \leq \mathrm{PCP}_{i}-\mathrm{PCP}_{j} \leq 500
\end{gathered}
$$

The import substitution involves two parties, i.e. the exporter and importer. More substantial emission reduction will be achieved if allowing the production of those exported products to be transferred to a third country with lower emission intensity than the original exporter and importer. The scenario of export transfer we consider is to minimize the total $\mathrm{NH}_{3}$ emissions in agricultural trade for each community. This is equivalent to taking total exports as given, reorganizing the production structure of exported goods within countries of the same community. Therefore, the objective function for export transfer is:

$$
\max _{\left\{\mathrm{EX}_{i}^{\mathrm{Af}}\right\}} \sum_{i=1}^{n} \mathrm{EX}_{i}^{\mathrm{AF}} \times \mathrm{EI}_{i}
$$

$$
\begin{gathered}
\text { s.t. } \sum_{i=1}^{n} \mathrm{EX}_{i}^{0}=\sum_{i=1}^{n} \mathrm{EX}_{i}^{\mathrm{AF}} \\
\mathrm{EX}_{i}^{\mathrm{AF}} \leq \mathrm{AC}_{i}+\mathrm{EX}_{i}^{0} \\
\mathrm{EX}_{i}^{0} \leq \sum_{j=1}^{n} I_{i j} \times \mathrm{EX}_{j}^{\mathrm{AF}}
\end{gathered}
$$


where $\mathrm{EX}_{i}^{0}$ is the original export of country $i$ before the adjustment of export transfer, $\mathrm{EX}_{i}^{\mathrm{AF}}$ is the new export of country $i$ after the adjustment, $I_{i j}$ is a dummy variable which equals 1 if and only if $-5 \leq \mathrm{AVT}_{i}-\mathrm{AVT}_{j} \leq 5$ and

$-500 \leq \mathrm{PCP}_{i}-\mathrm{PCP}_{j} \leq 500$. This first constraint keeps the total exports unchanged after the adjustment. The second constraint ensures the adjusted export of country $i$ does not exceed its total production capacity, measured by the sum of potential capacity and original exports. The last constraint guarantees that the original export of country $i$ is transferred to countries with similar annual temperature and precipitation.

We solve the above linear optimization problems to find the maximized emission reduction under export transfer and import substitution. The area of agricultural land and arable land is obtained from FAO (http://www.fao.org/ faostat/en/\#data/RL). Average annual temperature and rainfall are measured by the country-level averages from 1990 to 2012, which are available from the Climatic Research Unit of University of East Anglia (http://www.cru.uea.ac.uk/).

Technological advancement scenarios. We develop several $\mathrm{NH}_{3}$ emission control scenarios from the production side (reducing $\mathrm{N}$ fertilizer overuse, deep placement of fertilizers, enhanced-efficiency fertilizers, and improved animal manure storage and disposal) and consumption side (reducing food loss and waste, and replacing beef consumption with soy consumption).

(1) Estimating the potential of reducing $\mathrm{N}$ fertilizer overuse: $\mathrm{N}$ fertilizers are applied in unnecessarily high amounts in much of Asia (especially China), India, USA, and Europe. Overuse of $\mathrm{N}$ is much more severe in vegetables and fruits production, e.g., in China. Management of $\mathrm{N}$ during fruits and vegetable production has a much larger potential to improve compared to management during grain crop production. Mueller et al. ${ }^{61}$ estimated that nitrogen-fertilizer application on maize, wheat, and rice could decrease globally by $28 \%$ without impacting current yields. Considering the share of crop grain crop $\mathrm{N}$ in total $\mathrm{N}$ fertilizer use, we conservatively estimate that globally total $\mathrm{N}$ fertilizer use can be reduced by $14 \%$ to remove oversupply of nutrients and associated $\mathrm{Nr}$ losses. It is also noted that $\mathrm{N}$ fertilizer might not be reduced if there is not a regime to replace existing inorganic fertilizer applications.

(2) Estimating the potential of fertilizer deep placement and enhanced-efficiency fertilizers in grain crops: deep placement of $\mathrm{N}$ fertilizers can make $\mathrm{N}$ less susceptible to $\mathrm{NH}_{3}$ volatilization and more available to grain crops. A global meta-analysis found $55 \% \mathrm{NH}_{3}$ emission reduction achieved through deep placement ${ }^{62}$. A meta-analysis for China found $35 \% \mathrm{NH}_{3}$ emission reduction achieved for wheat and rice systems and $70 \%$ for maize. We conservatively estimate that $55 \%$ of grain production-related $\mathrm{NH}_{3}$ emissions can be reduced through deep placement. We obtain the contribution of grain production to total crop $\mathrm{NH}_{3}$ from Paulot et al. ${ }^{63}$. Urease inhibitors reduce the hydrolysis rate of urea fertilizers thus reducing $\mathrm{NH}_{3}$ emission rates by $40-70 \%$ depending on crop types and $\mathrm{N}$ application rates ${ }^{64}$. A global meta-analysis of field experiments reported $54 \% \mathrm{NH}_{3}$ emission reduction according to 198 observations ${ }^{62}$. A metaanalysis for China found $35 \% \mathrm{NH}_{3}$ emission reduction achieved for wheat and rice systems and $70 \%$ for maize ${ }^{65}$. A field research in Germany estimated $70 \%$ $\mathrm{NH}_{3}$ emission reduction ${ }^{66}$. We conservatively estimate that urease inhibitors will reduce $\mathrm{NH}_{3}$ emissions from grain crops by $54 \%$.

(3) Estimating the mitigation potential from livestock production: A global metaanalysis found the highest mitigation potential in dietary additive (35-54\%), urease inhibitor (24-69\%), manure acidification (89-95\%), and deep manure placement (94-99\%). Manure storage management could also significantly reduce $\mathrm{NH}_{3}$ emission by $70-82 \%{ }^{67}$. These mitigation measures should be taken simultaneously to effectively reduce $\mathrm{NH}_{3}$ emissions from livestock sectors. Despite great technological potential to reduce $\mathrm{NH}_{3}$ emissions, currently, manure around the world has been poorly managed ${ }^{68}$. For example, two-thirds of manure $\mathrm{N}$ produced in China are released as air pollutants ${ }^{69}$. We thus conservatively estimate that moderate improvements in manure management can reduce $\mathrm{NH}_{3}$ emissions by $35 \%$ and drastic improvements can reduce $70 \%$.

(4) Estimating the potential of eliminating food loss and waste: globally around $1 / 3$ of food produced are discarded during the food supply chain, food retail and consumption processes ${ }^{70}$. Reducing food waste and loss thus provides the opportunity for reducing agricultural emissions, especially in developed regions such as Europe and North America which already have relatively effective production management. We estimate the $\mathrm{NH}_{3}$ mitigation potential of eliminating food waste and loss for each country using the following equation:

$$
\begin{aligned}
& \text { Reduction }_{\mathrm{NH}_{3}}= \text { Reduction }_{\text {crop }_{\mathrm{NH}_{3}}}+\text { Reduction }_{\text {livestock }_{\mathrm{NH}_{3}}} \\
&= \text { Baseline }_{\text {crop }_{\mathrm{NH}_{3}}} \times \text { Waste }_{\text {LossRatio }_{\text {crop }}} \\
&+ \text { Baseline }_{\text {livestock }_{\mathrm{NH}_{3}}} \times \text { Waste_Loss_Ratio } \\
& \text { meat }
\end{aligned}
$$

where Baseline crop $_{\text {ww }}$ and Baseline livestock $_{N y}$ are national total $\mathrm{NH}_{3}$ emissions from $\mathrm{N}$ fertilizer application and livestock manure handling, respectively, for the year 2012 from the EDGAR inventory, Waste_Loss_Ratio ${ }_{\text {crop }}$ and Waste_Loss_Ratio ${ }_{\text {meat }}$ are the ratios of food loss and waste of cereal crops and animal meat products in this country. Waste_Loss_Ratio are estimated to include food loss and waste during agricultural production, postharvest handling and storage, processing and packaging, distribution and supermarket retail, and food consumption for each major region provided by Gustavsson et al. ${ }^{71}$.

(5) Estimating the potential of dietary shifts: beef, compared to other animal meat products, have much heavier nitrogen and water use footprints and greenhouse gas emissions ${ }^{72}$. $\mathrm{NH}_{3}$ emissions from beef manure alone contributes to $30 \%$ of agricultural $\mathrm{NH}_{3}$ emissions globally ${ }^{63}$. Replacing beef protein with other animal meat products or plant-based soybean protein can help reduce $\mathrm{NH}_{3}$ emissions. Here we consider the dietary change strategy of reducing beef consumption by $20 \%$ and $50 \%$, replacing that beef protein with soybean protein. The additional $\mathrm{NH}_{3}$ emissions brought by increased soybean cultivation are negligible. This is because the reduced animal feed production (mostly soy) should more than enough cover the increased soybean consumption, given that protein in animal feed does not end $100 \%$ in beef products. In addition, soybean is a $\mathrm{N}$-fixing crop and requires moderate $\mathrm{N}$ fertilizer application and emits little $\mathrm{NH}_{3}$ emissions. We obtain the contribution of beef production to $\mathrm{NH}_{3}$ emissions from animal production in the US, Europe, China and the world from Paulot et al. ${ }^{63}$. Then on top of EDGAR $\mathrm{NH}_{3}$ emission inventory, we impose a $20 \%$ and a $50 \%$ decrease of beef $\mathrm{NH}_{3}$ emissions by country.

(6) The MTFR scenario from GAINS model: we also applied the MTFR scenario by 2050 calculated from the GAINS (Greenhouse gas-Air pollution Interactions and Synergies) model (freely online from the website: https:// gains.iiasa.ac.at/models/gains_models3.html), which is developed by the International Institute for Applied Systems Analysis (IIASA) ${ }^{36}$. The GAINS model has been widely applied for assessing strategies of ammonia emission abatement ${ }^{73,74}$. The MTFR scenario in GAINS model assumes implementation of best available measures ignoring political or economic constraints but considering technical applicability that might vary regionally.

Uncertainty. Export-related $\mathrm{NH}_{3}$ emissions link local producers to global consumers along the entire supply chain. Based on multimodels, the uncertainty in this study mainly lies in the emissions inventory, economic data that includes the national accounts and interregional trade, and atmospheric transport model, and atmospheric model. Previous studies quantifying the uncertainty of national consumption-based carbon emissions (including imports and excluding the exports) are in the range $5-15 \%{ }^{75}$ and $2-16 \%^{76}$. The comparable uncertainty range of production- and consumption-based accounts indicate that a major source of uncertainty of MRIO is mainly the emission inventory rather than the economic and trade data ${ }^{77}$. According to Crippa et al. ${ }^{27}$, the uncertainty of EDGAR $\mathrm{NH}_{3}$ emissions is within a factor of $2-3$ for global major regions. This is mainly due to the uncertainty of adopted emission factors. Van Damme et al. ${ }^{3}$ has shown that the EDGAR inventory is able to capture $\mathrm{NH}_{3}$ emissions in the large source regions while it fails to capture strong point sources. Other observation-based constraints of $\mathrm{NH}_{3}$ emissions also have confirmed the validation of EDGAR $\mathrm{NH}_{3}$ inventory in China, USA, and Europe ${ }^{63,78}$. Future studies to further improve the accuracy of $\mathrm{NH}_{3}$ emissions in global inventories are urgently called for.

Reporting summary. Further information on research design is available in the Nature Research Reporting Summary linked to this article.

\section{Data availability}

The EDGAR v4.3.2 emission database is from Joint Research Centre, European Commission (https://data.jrc.ec.europa.eu/dataset/jrc-edgar-v432-ap-gridmaps). The global MRIO tables are from https://worldmrio.com/countrywise/. The Eora database is freely accessible from https://www.worldmrio.com/eora/. The United Nations Comtrade Database is available from https://comtrade.un.org/. The population and GDP data are available from the statistical database of the World Bank (https://data.worldbank.org). Country-level baseline mortality for the all-age group from the Institute for Health Metrics and Evaluation (http://ghdx.healthdata.org/ihme_data). The area of agricultural land and arable land is obtained from FAO (http://www.fao.org/faostat/en/\#data/RL) Average annual temperature and precipitation data are available from the Climatic Research Unit of University of East Anglia (http://www.cru.uea.ac.uk/). The GAINS model is from the International Institute for Applied Systems Analysis (IIASA) (https:// gains.iiasa.ac.at/models/gains_models3.htm).

\section{Code availability}

The GEOS-Chem model code is open-source https://doi.org/10.5281/zenodo.1343547. Codes for reproducing the results in this study are available from https:/github.com/ KeLi218/NH3_emissions/ and also available from corresponding authors on reasonable request.

Received: 29 July 2019; Accepted: 16 August 2021; Published online: 05 November 2021 


\section{References}

1. Plautz, J. Piercing the haze. Science 361, 1060-1063 (2018)

2. Liu, M. et al. Ammonia emission control in China would mitigate haze pollution and nitrogen deposition, but worsen acid rain. Proc. Natl Acad. Sci. USA 116, 7760-7765 (2019).

3. Van Damme, M. et al. Industrial and agricultural ammonia point sources exposed. Nature 564, 99-103 (2018).

4. Bauer, S. E., Tsigaridis, K. \& Miller, R. Significant atmospheric aerosol pollution caused by world food cultivation. Geophys. Res. Lett. 43, 5394-5400 (2016).

5. $\mathrm{Wu}$, Y. et al. $\mathrm{PM}_{2.5}$ pollution is substantially affected by ammonia emissions in China. Environ. Pollut. 218, 86-94 (2016).

6. Lelieveld, J., Evans, J. S., Fnais, M., Giannadaki, D. \& Pozzer, A. The contribution of outdoor air pollution sources to premature mortality on a global scale. Nature 525, 367-371 (2015).

7. Tang, Y. S. et al. Pan-European rural atmospheric monitoring network shows dominance of $\mathrm{NH}_{3}$ gas and $\mathrm{NH}_{4} \mathrm{NO}_{3}$ aerosol in inorganic pollution load. Atmos. Chem. Phys. https://doi.org/10.5194/acp-2020-275-R, 1-61 (2020).

8. Guo, Y. X. et al. Air quality, nitrogen use efficiency and food security in China are improved by cost-effective agricultural nitrogen management. Nat. Food $\mathbf{1}$, 648-658 (2020).

9. Erisman, J. W., Sutton, M. A., Galloway, J., Klimont, Z. \& Winiwarter, W. How a century of ammonia synthesis changed the world. Nat. Geosci. 1, 636-639 (2008).

10. Xu, R. et al. Global ammonia emissions from synthetic nitrogen fertilizer applications in agricultural systems: Empirical and process-based estimates and uncertainty. Glob. Change Biol. 25, 314-326 (2019).

11. Li, K., Liao, H., Zhu, J. \& Moch, J. M. Implications of RCP emissions on future $\mathrm{PM}_{2.5}$ air quality and direct radiative forcing over China. J. Geophys. Res. Atmos. 121, 12985-13008 (2016).

12. D'Odorico, P., Carr, J. A., Laio, F., Ridolfi, L. \& Vandoni, S. Feeding humanity through global food trade. Earth's Fut. 2, 458-469 (2014).

13. Zhao, X. L. et al. Linking agricultural GHG emissions to global trade network. Earth's Fut. 8, eEF001361 (2020).

14. Oita, A. et al. Substantial nitrogen pollution embedded in international trade. Nat. Geosci. 9, 111-115 (2016).

15. Davis, S. J. \& Caldeira, K. Consumption-based accounting of $\mathrm{CO}_{2}$ emissions. Proc. Natl Acad. Sci. USA 107, 5687-5692 (2010).

16. Peters, G. P., Minx, J. C., Weber, C. L. \& Edenhofer, O. Growth in emission transfers via international trade from 1990 to 2008. Proc. Nat. Acad. Sci. USA 108, 8903-8908 (2011).

17. Kanemoto, K., Moran, D. \& Hertwich, E. Mapping the carbon footprint of nations. Environ. Sci. Technol. 50, 10512-10517 (2016).

18. Zhang, B. et al. Consumption-based accounting of global anthropogenic $\mathrm{CH}_{4}$ emissions. Earth's Fut. 6, 1349-1363 (2018).

19. Meng, J. et al. Globalization and pollution: tele-connecting local primary $\mathrm{PM}_{2.5}$ emissions to global consumption. P. R. Soc. A. 472, 20160380 (2016).

20. Moran, D. \& Kanemoto, K. Tracing global supply chains to air pollution hotspots. Environ. Res. Lett. 11, 094017 (2016).

21. Lin, J. et al. China's international trade and air pollution in the United States. Proc. Natl. Acad. Sci. USA 111, 1736-1741 (2014).

22. Zhang, Q. et al. Transboundary health impacts of transported global air pollution and international trade. Nature 543, 705-709 (2017).

23. Takahashi, K. et al. Production-based emissions, consumption-based emissions and consumption-based health impacts of $\mathrm{PM}_{2.5}$ carbonaceous aerosols in Asia. Atmos. Environ. 97, 406-415 (2014).

24. Liang, S. et al. Consumption-based human health impacts of primary $\mathrm{PM}_{2.5}$ : the hidden burden of international trade. J. Clean. Prod. 167, 133-139 (2017).

25. Xiao, Y., Murray, J. \& Lenzen, M. International trade linked with disease burden from airborne particulate pollution. Resour. Conserv. Recycl. 129, 1-11 (2018).

26. Torreggiani, S., Mangioni, G., Puma, M. J. \& Fagiolo, G. Identifying the community structure of the food-trade international multi-network. Environ. Res. Lett. 13, 054026 (2018).

27. Crippa, M. et al. Gridded emissions of air pollutants for the period 1970-2012 within EDGAR v4.3.2. Earth Syst. Sci. Data 10, 1987-2013 (2018).

28. Brauer, M. et al. Ambient air pollution exposure estimation for the global burden of disease 2013. Environ. Sci. Technol. 50, 79-88 (2015).

29. Girvan, M. \& Newman, M. E. Community structure in social and biological networks. Proc. Natl. Acad. Sci. USA 99, 7821-7826 (2002).

30. Barabási, A. L. \& Albert, R. Emergence of scaling in random networks. Science 286, 509-512 (1999).

31. Albert, R., Jeong, H. \& Barabási, A. L. Error and attack tolerance of complex networks. Nature 406, 378-382 (2000).

32. Kitsak, M. et al. Identification of influential spreaders in complex networks. Nat. Phys. 6, 888-893 (2010).

33. Nordhaus, W. Climate clubs: overcoming free-riding in international climate policy. Am. Econ. Rev. 105, 1339-1370 (2015).
34. United Nations Environment Programme. Frontiers 2018/19 emerging issues of environmental concern, Nairobi. https://www.unep.org/resources/frontiers201819-emerging-issues-environmental-concern (2019).

35. Chinese State Council. Three-year action plan on defending the blue sky (in Chinese). http://www.gov.cn/zhengce/content/2018-07/03/ content_5303158.htm (2018).

36. Klimont, Z., \& Winiwarter, W. in Costs of Ammonia Abatement and the Climate Co-benefits (eds Reis, S., Howard, C. \& Sutton, M.A), 233-261 (Springer, 2015).

37. The Fourth United Nations Environment Assembly. United Nations Environment Assembly of the United Nations Environment Programme: sustainable nitrogen management. https://papersmart.unon.org/resolution/ uploads/k1900699.pdf (2019).

38. James, W. J. et al. Brief history of agricultural systems modeling. Agric. Syst. 155, 240-254 (2017).

39. Kellogg, R. L., Lander, C. H., Moffitt, D. C. \& Gollehon, N. Manure Nutrients Relative to the Capacity of Cropland and Pastureland to Assimilate Nutrients: Spatial and Temporal Trends for the United States (Natural Resources Conservation Service/Economic Research Service/US Department of Agriculture's Natural Resources Conservation Service, 2000).

40. Xia, L., Lam, S. K., Yan, X. \& Chen, D. How does recycling of livestock manure in agroecosystems affect crop productivity, reactive nitrogen losses, and soil carbon balance? Environ. Sci. Technol. 51, 7450-7457 (2017).

41. Lenzen, M., Moran, D., Kanemoto, K. \& Geschke, A. Building Eora: a global multi-region input-output database at high country and sector resolution. Econ. Syst. Res. 25, 20-49 (2013).

42. Lenzen, M., Kanemoto, K., Moran, D. \& Geschke, A. Mapping the structure of the world economy. Environ. Sci. Technol. 46, 8374-8381 (2012).

43. Kanemoto, K., Moran, D., Lenzen, M. \& Geschke, A. International trade undermines national emission reduction targets: new evidence from air pollution. Glob. Environ. Change 24, 52-59 (2014).

44. Wiedmann, T. O. \& Lenzen, M. Environmental and social footprints of international trade. Nat. Geosci. 11, 314-321 (2018).

45. Chen, B., Han, M. Y., Peng, K., Zhou, S. L. \& Chen, G. Q. Global land-water nexus: agricultural land and freshwater use embodied in worldwide supply chains. Sci. Total Environ. 613, 931-943 (2018).

46. Maluck, J. \& Donner, R. V. A network of networks perspective on global trade. PLoS ONE 10, e0133310 (2015).

47. Sartori, M. \& Schiavo, S. Connected we stand: a network perspective on trade and global food security. Food Policy 57, 114-127 (2015).

48. Ercsey-Ravasz, M., Toroczkai, Z., Lakner, Z. \& Baranyi, J. Complexity of the international agro-food trade network and its impact on food safety. PLoS ONE 7, e37810 (2012)

49. Travis, K. R. et al. Why do models overestimate surface ozone in the Southeast United States? Atmos. Chem. Phys. 16, 13561-13577 (2016).

50. Bouwman, A. F. \& Van Der Hoek, K. W. Scenarios of animal waste production and fertilizer use and associated ammonia emission for the developing countries. Atmos. Environ. 31, 4095-4102 (1997).

51. Li, K. et al. Anthropogenic drivers of 2013-2017 trends in summer surface ozone in China. Proc. Natl. Acad. Sci. USA 116, 422-427 (2019).

52. Lenzen, M. et al. The carbon footprint of global tourism. Nat. Clim. Change $\mathbf{8}$ 522-528 (2018)

53. Park, R. J., Jacob, D. J., Kumar, N. \& Yantosca, R. M. Regional visibility statistics in the United States: natural and transboundary pollution influences, and implications for the Regional Haze Rule. Atmos. Environ. 40, 5405-5423 (2006).

54. Pye, H. O. T. et al. Effect of changes in climate and emissions on future sulfate-nitrate-ammonium aerosol levels in the United States. J. Geophys. Res. 114, D1 (2009).

55. Van Donkelaar, A. et al. Global estimates of ambient fine particulate matter concentrations from satellite-based aerosol optical depth: development and application. Environ. Health Perspect. 118, 847-855 (2010).

56. Shah, V. et al. Chemical feedbacks weaken the wintertime response of particulate sulfate and nitrate to emissions reductions over the eastern United States. Proc. Natl. Acad. Sci. USA 115, 8110-8115 (2018).

57. Zhai, S. et al. Control of particulate nitrate air pollution in China. Nat. Geosci. 14, 389-395 (2021)

58. Heald, C. L. et al. Atmospheric ammonia and particulate inorganic nitrogen over the United States. Atmos. Chem. Phys. 12, 10295-10312 (2012).

59. Burnett, R. T. et al. An integrated risk function for estimating the global burden of disease attributable to ambient fine particulate matter exposure. Environ. Health Perspect. 122, 397-403 (2014).

60. Chafe, Z. A. et al. Household cooking with solid fuels contributes to ambient $\mathrm{PM}_{2.5}$ air pollution and the burden of disease. Environ. Health Perspect. 122, 1314-1320 (2014).

61. Mueller, N. et al. Closing yield gaps through nutrient and water management Nature 490, 254-257 (2012)

62. Pan, B., Lam, S. K., Mosier, A., Luo, Y. \& Chen, D. Ammonia volatilization from synthetic fertilizers and its mitigation strategies: a global synthesis. Agric. Ecosyst. Environ. 232, 283-289 (2016). 
63. Paulot, F. et al. Ammonia emissions in the United States, European Union, and China derived by high-resolution inversion of ammonium wet deposition data: interpretation with a new agricultural emissions inventory (MASAGE_NH3). J. Geophys. Res. 119, 4343-4364 (2014).

64. Trenkel, M. E. Slow- and Controlled-Release and Stabilized Fertilizers: An Option for Enhancing Nutrient Use Efficiency in Agriculture (International Fertilizer Industry Association, 2010).

65. Xia, L., Ti, C., Li, B., Xia, Y. \& Yan, X. Greenhouse gas emissions and reactive nitrogen releases during the life-cycles of staple food production in China and their mitigation potential. Sci. Total Environ. 556, 116-125 (2016).

66. Schraml, M., Gutser, R., Maier, H. \& Schmidhalter, U. Ammonia loss from urea in grassland and its mitigation by the new urease inhibitor 2-NPT. J. Agric. Sci. 154, 1453-1462 (2016).

67. Ti, C., Xia, L., Chang, S. X. \& Yan, X. Potential for mitigating global agricultural ammonia emission: a meta-analysis. Environ. Pollut. 245, 141-148 (2019).

68. Hou, Y., Velthof, G. L. \& Oenema, O. Mitigation of ammonia, nitrous oxide and methane emissions from manure management chains: a meta-analysis and integrated assessment. Glob. Change Biol 21, 1293-1312 (2015).

69. Bai, Z. et al. Livestock housing and manure storage need to be improved in China. Environ. Sci. Technol. 51, 8212-8214 (2017).

70. Bond, M., Meacham, T., Bhunnoo, R. \& Benton, T. Food Waste Within Global Food Systems (Global Food Security Swindon, UK, 2013)

71. Gustavsson, J., Cederberg, C., Sonesson, U., Otterdijk, R. \& Meybeck, A. Global Food Losses and Food Waste (Swedish Institute for Food and Biotechnology and FAO, 2011).

72. Eshel, G., Shepon, A., Makov, T. \& Milo, R. Land, irrigation water, greenhouse gas, and reactive nitrogen burdens of meat, eggs, and dairy production in the United States. Proc. Natl. Acad. Sci. USA 111, 11996-12001 (2014).

73. Backes, A. M., Aulinger, A., Bieser, J., Matthias, V. \& Quante, M. Ammonia emissions in Europe, part II: How ammonia emission abatement strategies affect secondary aerosols. Atmos. Environ. 126, 153-161 (2016).

74. Zhang, N. et al. Reducing ammonia emissions from dairy cattle production via cost-effective manure management techniques in China. Environ. Sci. Technol. 53, 11840-11848 (2019).

75. Hertwich, E. G. \& Peters, G. P. Carbon footprint of nations: a global, tradelinked analysis. Environ. Sci. Technol. 43, 6414-6420 (2009).

76. Rodrigues, J. F., Moran, D., Wood, R. \& Behrens, P. Uncertainty of consumptionbased carbon accounts. Environ. Sci. Technol. 52, 7577-7586 (2018).

77. Owen, A., Steen-Olsen, K., Barrett, J., Wiedmann, T. \& Lenzen, M. A structural decomposition approach to comparing MRIO databases. Econ. Syst. Res 26, 262-283 (2014).

78. Zhang, L. et al. Agricultural ammonia emissions in China: reconciling bottom-up and top-down estimates. Atmos. Chem. Phys. 18, 339-355 (2018).over-supply

\section{Acknowledgements}

This study was supported by the National Natural Science Foundation of China (Grant nos. 72088101 and 71774161). K.L. was supported by the National Key Research and Development Program of China (grant 2019YFA0606800). R.M. was supported by the National Key Research and Development Program of China (grant 2020YFA0608603) and the National Natural Science Foundation of China (72134006). J.M. was supported by the Natural Environment Research Council (NE/V002414/1) and the National Natural Science Foundation of China (72173133). Y.Guo acknowledges support from the Princeton University Graduate School's Dean's Completion Fellowship and Peking University's PKU-IIASA fellowship.

\section{Author contributions}

B.Z., K.L., J.M. and R.M. designed the study. R.M., B.Z., K.L. and Y.Guo performed the research. J.M., X.Z., C.H.G, S.L., G.Chen and Y.G. contributed to the analysis and interpretation of results. All authors wrote and edited the manuscript.

\section{Competing interests}

The authors declare no competing interests.

\section{Additional information}

Supplementary information The online version contains supplementary material available at https://doi.org/10.1038/s41467-021-25854-3.

Correspondence and requests for materials should be addressed to Bo Zhang or Jing Meng.

Peer review information Nature Communications thanks Rosa Duarte and the other, anonymous, reviewer(s) for their contribution to the peer review of this work. Peer reviewer reports are available.

Reprints and permission information is available at http://www.nature.com/reprints

Publisher's note Springer Nature remains neutral with regard to jurisdictional claims in published maps and institutional affiliations.

(c) (1) Open Access This article is licensed under a Creative Commons Attribution 4.0 International License, which permits use, sharing, adaptation, distribution and reproduction in any medium or format, as long as you give appropriate credit to the original author(s) and the source, provide a link to the Creative Commons license, and indicate if changes were made. The images or other third party material in this article are included in the article's Creative Commons license, unless indicated otherwise in a credit line to the material. If material is not included in the article's Creative Commons license and your intended use is not permitted by statutory regulation or exceeds the permitted use, you will need to obtain permission directly from the copyright holder. To view a copy of this license, visit http://creativecommons.org/ licenses/by/4.0/.

(C) The Author(s) 2021, corrected publication 2021 